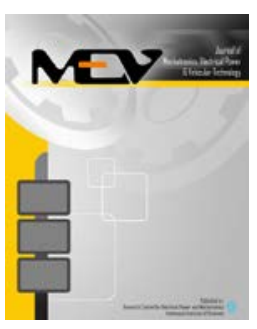

Journal of Mechatronics, Electrical Power, and Vehicular Technology

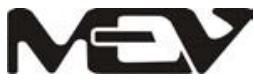

\title{
A CFD MOdel For ANALYSis OF PERFormanCE, WATER AND THERMAL DISTRIBUTION, AND MECHANICAL RELATED FAILURE IN PEM FUEL CELLS
}

\author{
Maher A.R. Sadiq Al-Baghdadi* \\ Department of Mechanical Engineering, Faculty of Engineering, University of Kufa, \\ Najaf, Kufa, Iraq
}

Received 25 January 2016; received in revised form 03 May 2016; accepted 08 May 2016

Published online 29 July 2016

\begin{abstract}
This paper presents a comprehensive three-dimensional, multi-phase, non-isothermal model of a Proton Exchange Membrane (PEM) fuel cell that incorporates significant physical processes and key parameters affecting the fuel cell performance. The model construction involves equations derivation, boundary conditions setting, and solution algorithm flow chart. Equations in gas flow channels, gas diffusion layers (GDLs), catalyst layers (CLs), and membrane as well as equations governing cell potential and hygro-thermal stresses are described. The algorithm flow chart starts from input of the desired cell current density, initialization, iteration of the equations solution, and finalizations by calculating the cell potential. In order to analyze performance, water and thermal distribution, and mechanical related failure in the cell, the equations are solved using a computational fluid dynamic (CFD) code. Performance analysis includes a performance curve which plots the cell potential (Volt) against nominal current density $\left(\mathrm{A} / \mathrm{cm}^{2}\right)$ as well as losses. Velocity vectors of gas and liquid water, liquid water saturation, and water content profile are calculated. Thermal distribution is then calculated together with hygro-thermal stresses and deformation. The CFD model was executed under boundary conditions of $20^{\circ} \mathrm{C}$ room temperature, $35 \%$ relative humidity, and 1 MPA pressure on the lower surface. Parameters values of membrane electrode assembly (MEA) and other base conditions are selected. A cell with dimension of $1 \mathrm{~mm}$ x $1 \mathrm{~mm}$ x $50 \mathrm{~mm}$ is used as the object of analysis. The nominal current density of $1.4 \mathrm{~A} / \mathrm{cm}^{2}$ is given as the input of the CFD calculation. The results show that the model represents well the performance curve obtained through experiment. Moreover, it can be concluded that the model can help in understanding complex process in the cell which is hard to be studied experimentally, and also provides computer aided tool for design and optimization of PEM fuel cells to realize higher power density and lower cost.
\end{abstract}

Key words: CFD; PEM; fuel cell; multi-phase; hygro thermal stress.

\section{INTRODUCTION}

Water management is one of the critical operation issues in proton exchange membrane fuel cells (PMFCs). Spatially varying concentrations of water in both vapour and liquid form are expected throughout the cell because of varying rates of production and transport. Water emanates from two sources i.e. the product water from the oxygen-reduction reaction in the cathode catalyst layer and the humidification water carried by the inlet streams or injected into the fuel cell [1]. One of the main difficulties in managing water in a PEMFC is the conflicting requirements of the membrane and the catalyst

* Corresponding Author. Tel: +96-47719898955

E-mail: mahirar.albaghdadi@uokufa.edu.iq gas diffusion layer (GDL). On the cathode side, excessive liquid water may block or flood the pores of the catalyst layer, the GDL or even the gas channel, thereby inhibiting or even completely blocking oxygen mass transfer. On the anode side, as water is dragged toward the cathode via electro-osmotic transport, dehumidification of the membrane may occur, resulting in deterioration of protonic conductivity. In the extreme case of complete drying, local burnout of the membrane can result. Devising better water management is a key issue.

Thermal management is also required to remove the heat produced by the electrochemical reaction in order to prevent drying out of the membrane, which in turn can result not only in 
reduced performance but also in eventual rupture of the membrane [2]. Thermal management is also essential for controlling the water evaporation or condensation rates. The difficult experimental environment of fuel cell systems has stimulated efforts to develop models that could simulate and predict multi-dimensional coupled transport of reactants, heat, and charged species using CFD methods. A comprehensive model should include equations and numerical relations needed to fully define fuel cell behavior over the range of interest.

Early multidimensional models described gas transport in the flow channels, gas diffusion layers, and the membrane [3-5]. Iranzo et al. [6] developed a multi-phase, two-dimensional model to describe the liquid water saturation and flood effect, and have been studied transport limitations due to water build up in the cathode catalyst region. Djilali [7] developed a CFD multiphase model of a PEMFC. This model provides information on liquid water saturation and flood under various conditions, however it does not account for water dissolved in the ion-conducting polymer to calculate water content through the membrane. Hu et al. [8] and Fouquet [9] developed an isothermal, three-dimensional, twophase model for a PEMFC. Their model describes the transport of liquid water within the porous electrodes and water dissolved in the ionconducting polymer. The model is restricted to constant cell temperature.

The need for improving lifetime of PEMFCs necessitates that the failure mechanisms be clearly understood, so that new designs can be introduced to improve long-term performance. Weber and Newman [10] developed onedimensional model to study the stresses development in the fuel cell. Bograchev et al. [11] studied the hygro and thermal stresses in the fuel cell caused by step-changes of temperature and relative humidity. However, their model is two-dimensional. In addition, constant temperature was assumed at each surface of the membrane.

An operating fuel cell has various local conditions of temperature, humidity, and power generation across the active area of the fuel cell. Nevertheless, no models have yet been published to incorporate hygro-thermal stresses in threedimension. Therefore, in order to acquire a complete understanding of the damage mechanisms in the membranes, mechanical response under steady-state hygro-thermal stresses should be modelled and studied under real cell operation conditions.

\section{MODEL DESCRIPTION}

This paper presents a comprehensive threedimensional, multi-phase, non-isothermal model of a PEMFC. It accounts for both gas and liquid phase. It includes the transport of gaseous species, liquid water, protons, energy, and water dissolved in the ion-conducting polymer. The model features an algorithm to improve prediction of the local current density distribution. It takes into account convection and diffusion of different species, heat transfer, and electrochemical reactions. It also incorporates the effect of hygrothermal stresses.

More specifically, this paper describes the development of the model, the determination of properties for use in the model, the validation of the model using experimental data, and the application of the model to explain observed experimental phenomena. Formulas governing the process inside a PEMFC have already been disclosed in the previous papers [20-24]. In order to make it self-content to some extent, some important equations are re-presented.

\section{A. Computational Domain}

In order to save computing resources and shorten simulation times, computational domain is limited to one straight flow channel. It consists of gas flow channels, and membrane electrode assembly (MEA) as shown in Figure 1.

\section{B. Model Equations}

1) Gas Flow Channels

In the fuel cell channels, the gas-flow field is obtained by solving the steady-state NavierStokes equations. The continuity equations for the gas phase and the liquid phase inside the channel is given by:

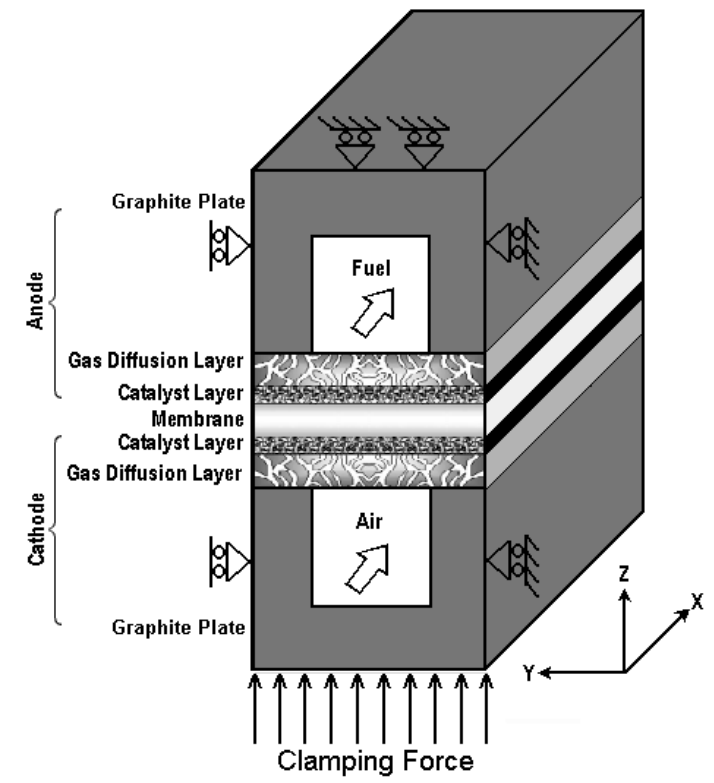

Figure 1. Computational domain 


$$
\begin{aligned}
& \nabla \cdot\left(r_{g} \rho_{g} \mathbf{u}_{g}\right)=0 \\
& \nabla \cdot\left(r_{l} \rho_{l} \mathbf{u}_{l}\right)=0
\end{aligned}
$$

The following momentum equations are solved in the channels, and they share the same pressure field.

$$
\begin{aligned}
& \nabla \cdot\left(\rho_{g} \mathbf{u}_{g} \otimes \mathbf{u}_{g}-\mu_{g} \nabla \mathbf{u}_{g}\right)= \\
& -\nabla r_{g}\left(P+\frac{2}{3} \mu_{g} \nabla \cdot \mathbf{u}_{g}\right)+\nabla \cdot\left[\mu_{g}\left(\nabla \mathbf{u}_{g}\right)^{T}\right] \\
& \nabla \cdot\left(\rho_{l} \mathbf{u}_{l} \otimes \mathbf{u}_{l}-\mu_{l} \nabla \mathbf{u}_{l}\right)= \\
& -\nabla r_{l}\left(P+\frac{2}{3} \mu_{l} \nabla \cdot \mathbf{u}_{l}\right)+\nabla \cdot\left[\mu_{l}\left(\nabla \mathbf{u}_{l}\right)^{T}\right]
\end{aligned}
$$

The mass balance is described by the divergence of the mass flux through diffusion and convection. Multiple species are considered in the gas phase only, and the species conservation equation in multi-component, multi-phase flow can be written in the following expression for species $i$ :

$$
\nabla \cdot\left[\begin{array}{r}
-r_{g} \rho_{g} y_{i} \sum_{j=1}^{N} D_{i j} \frac{M}{M_{j}}\left[\left(\nabla y_{j}+y_{j} \frac{\nabla M}{M}\right)+\left(x_{j}-y_{j}\right) \frac{\nabla P}{P}\right]+ \\
r_{g} \rho_{g} y_{i} \cdot \mathbf{u}_{g}+D_{i}^{T} \frac{\nabla T}{T}
\end{array}\right]=0
$$

where the subscript $i$ denotes oxygen at the cathode side and hydrogen at the anode side, and $j$ is water vapour in both cases. Nitrogen is the third species at the cathode side.

The Maxwell-Stefan diffusion coefficients of any two species are dependent on temperature and pressure. They can be calculated according to the empirical relation based on kinetic gas theory [12]:

$$
D_{i j}=\frac{T^{1.75} \times 10^{-3}}{P\left[\left(\sum_{k} V_{k i}\right)^{1 / 3}+\left(\sum_{k} V_{k j}\right)^{1 / 3}\right]^{2}}\left[\frac{1}{M_{i}}+\frac{1}{M_{j}}\right]^{1 / 2}
$$

In this equation, pressure is in [atm] and the binary diffusion coefficient is in $\left[\mathrm{cm}^{2} / \mathrm{s}\right]$. The values for $\left(\sum V_{k i}\right)$ are given by Fuller et al. [12]. The temperature field is obtained by solving the convective energy equation:

$$
\nabla \cdot\left(r_{g}\left(\rho_{g} C p_{g} \mathbf{u}_{g} T-k_{g} \nabla T\right)\right)=0
$$

The gas phase and the liquid phase are assumed to be in thermodynamic equilibrium; hence the temperature of the liquid water is the same as the gas phase temperature.

\section{2) Gas Diffusion Layers (GDL)}

The physics of multiple phases through a porous medium is further complicated here with phase change and the sources and sinks associated with the electrochemical reaction. The equations used to describe transport in the GDL are given below. Mass transfer in the form of evaporation $\quad\left(\dot{m}_{\text {phase }}>0\right)$ and condensation $\left(\dot{m}_{\text {phase }}<0\right)$ is assumed, so that the mass balance equations for both phases are:

$$
\begin{aligned}
& \nabla \cdot\left((1-\text { sat }) \rho_{g} z \mathbf{u}_{g}\right)=\dot{m}_{\text {phase }} \\
& \nabla \cdot\left(\text { sat. } \rho_{l} z \mathbf{u}_{l}\right)=\dot{m}_{\text {phase }}
\end{aligned}
$$

The momentum equation for the gas phase reduces to Darcy's law, which is based on the relative permeability for the gas phase. The relative permeability accounts for the reduction in pore space available for one phase due to the existence of the second phase [7].

The momentum equation for the gas phase inside the GDL becomes:

$$
\mathbf{u}_{g}=-(1-s a t) \frac{K p}{\mu_{g}} \nabla P
$$

Two liquid water transport mechanisms are considered; shear, which drags the liquid phase along with the gas phase in the direction of the pressure gradient, and capillary forces, which drive liquid water from high to low saturation regions [7]. Therefore, the momentum equation for the liquid phase inside the GDL becomes:

$$
\mathbf{u}_{l}=-\frac{K P_{l}}{\mu_{l}} \nabla P+\frac{K P_{l}}{\mu_{l}} \frac{\partial P_{C}}{\partial s a t} \nabla s a t
$$

The functional variation of capillary pressure with saturation is prescribed following Leverett [7] who has shown that:

$$
\begin{aligned}
P_{c}= & \tau\left(\frac{\varepsilon}{K P}\right)^{1 / 2}(1.417(1-\text { sat })- \\
& 2.121-\text { sat } 2+1.2631-\text { sat } 3
\end{aligned}
$$

The liquid phase consists of pure water, while the gas phase has multi components. The transport of each species in the gas phase is governed by a general convection-diffusion equation in conjunction which the StefanMaxwell equations to account for multi species diffusion:

$$
\nabla \cdot\left[\begin{array}{r}
-(1-s a t) \rho_{g} g y_{i} \sum_{j=1}^{N} D_{i j} \frac{M}{M_{j}}\left[\left(\nabla y_{j}+y_{j} \frac{\nabla M}{M}\right)+\left(x_{j}-y_{j}\right) \frac{\nabla P}{P}\right]+ \\
(1-s a t) \rho_{g} y_{i} \cdot \mathbf{u}_{g}+\varepsilon D_{i}^{T} \frac{\nabla T}{T}
\end{array}\right]=\dot{m}_{\text {phase }}
$$

In order to account for geometric constraints of the porous media, the diffusivities are corrected using the Bruggemann correction formula [3]: 


$$
D_{i j}^{e f f}=D_{i j} \times \varepsilon^{1.5}
$$

The heat transfer in the gas diffusion layers is governed by the energy equation as follows:

$$
\begin{aligned}
& \nabla \cdot\left((1-\text { sat })\left(\rho_{g} \varepsilon C p_{g} \mathbf{u}_{g} T-k_{\text {eff }, g} \varepsilon \nabla T\right)\right)= \\
& \varepsilon \beta\left(T_{\text {solid }}-T\right)-\dot{c m}_{\text {phase }} \Delta H_{\text {evap }}
\end{aligned}
$$

where the term $\left(\varepsilon \beta\left(T_{\text {solid }}-T\right)\right.$ ), on the right hand side, accounts for the heat exchange to and from the solid matrix of the GDL. $\beta$ is a modified heat transfer coefficient that accounts for the convective heat transfer in $\left[\mathrm{W} / \mathrm{m}^{2}\right]$ and the specific surface area $\left[\mathrm{m}^{2} / \mathrm{m}^{3}\right]$ of the porous medium [3]. Hence, the unit of $\beta$ is $\left[\mathrm{W} / \mathrm{m}^{3}\right]$.

The gas phase and the liquid phase are assumed to be in thermodynamic equilibrium, i.e., the liquid water and the gas phase are at the same temperature. The potential distribution in the GDLs is governed by:

$$
\nabla \cdot\left(\lambda_{e} \nabla \phi\right)=0
$$

In order to determine the magnitude of phase change inside the GDL, expressions are required to relate the level of over- and undersaturation as well as the amount of liquid water present to the amount of water undergoing phase change. In the present work, the procedure of Djilali [7] was used to determine the magnitude of phase change inside the GDL.

\section{3) Catalyst Layers (CLs)}

The catalyst layer is treated as a thin interface, where sink and source terms for the reactants are implemented. Due to the infinitesimal thickness, the source terms are implemented in the last grid cell of the porous medium. The sink terms for oxygen and hydrogen are given by:

$$
S_{\mathrm{O}_{2}}=-\frac{M_{\mathrm{O}_{2}}}{4 F} i_{C} \quad S_{\mathrm{H}_{2}}=-\frac{M_{\mathrm{H}_{2}}}{2 F} i_{a}
$$

The production of water is modelled as a source terms, and hence can be written as:

$$
S_{\mathrm{H}_{2} \mathrm{O}}=\frac{M_{\mathrm{H}_{2} \mathrm{O}}}{2 \mathrm{~F}} i_{C}
$$

The generation of heat in the cell is due to entropy changes as well as irreversibilities due to the activation overpotential [13]:

$$
\dot{q}=\left[\frac{T(-\Delta s)}{n_{e} F}+\eta_{a c t, c}\right] i_{C}
$$

The local current density in the CLs is modelled by the Butler-Volmer equation [14, 15];

$$
\begin{aligned}
& i_{c}=i_{o, c}^{r e f}\left(\frac{C_{O_{2}}}{C_{O_{2}}^{r e f}}\right)\left[\exp \left(\frac{\alpha_{a} F}{R T} \eta_{a c t, c}\right)+\exp \left(-\frac{\alpha_{c} F}{R T} \eta_{a c t, c}\right)\right] \\
& i_{a}=i_{o, a}^{r e f}\left(\frac{C_{H_{2}}}{C_{H_{2}}^{r e f}}\right)^{1 / 2}\left[\exp \left(\frac{\alpha_{a} F}{R T} \eta_{a c t, a}\right)+\exp \left(-\frac{\alpha_{c} F}{R T} \eta_{a c t, a}\right)\right]
\end{aligned}
$$

\section{4) Membrane}

The balance between the electro-osmotic drag of water from anode to cathode and back diffusion from cathode to anode yields the net water flux through the membrane:

$$
N_{W}=n_{d} M_{H_{2} O} \frac{i}{F}-\nabla \cdot\left(\rho D_{W} \nabla c_{W}\right)
$$

The water diffusivity in the polymer can be calculated as follow [6]:

$$
D_{W}=1.3 \times 10^{-10} \exp \left[2416\left(\frac{1}{303}-\frac{1}{T}\right)\right]
$$

The variable $C_{W}$ represents the number of water molecules per sulfonic acid group (i.e. mol $\mathrm{H}_{2} \mathrm{O}$ /equivalent $\mathrm{SO}_{3}{ }^{-1}$ ). The water content in the electrolyte phase is related to water vapour activity via $[8,9]$ :

$$
\begin{array}{ll}
c_{W}=0.043+17.81 a-39.85 a^{2}+36.0 a^{3} & (0<a \leq 1) \\
c_{W}=14.0+1.4(a-1) & (1<a \leq 3) \\
c_{W}=16.8 & (a \geq 3)
\end{array}
$$

The water vapour activity given by:

$$
a=\frac{x_{W} P}{P_{\text {sat }}}
$$

For heat transfer purposes, the membrane is considered a conducting solid, which means that the transfer of energy associated with the net water flux through the membrane is neglected. Heat transfer in the membrane is determined by:

$$
\nabla \cdot\left(k_{\text {mem }} \cdot \nabla T\right)=0
$$

The potential loss in the membrane is due to resistance to proton transport across membrane, and determined by:

$$
\nabla \cdot\left(\lambda_{m} \nabla \phi\right)=0
$$

\section{5) Cell Potential}

Electrical energy is obtained only when a current is drawn, but the actual cell potential $\left(E_{\text {cell }}\right)$ is decreased from its equilibrium thermodynamic potential (E) because of irreversible losses. The cell potential is obtained by subtracting all over potentials (losses) from 
the equilibrium thermodynamic potential as the following expression $[16,17]$ :

$$
E_{\text {cell }}=E-\eta_{\text {act }}-\eta_{\text {ohm }}-\eta_{\text {mem }}-\eta_{\text {Diff }}
$$

The equilibrium potential is determined using the Nernst equation [18]:

$$
\begin{array}{r}
E=1.229-0.83 \times 10^{-3}(T-298.15)+ \\
\quad 4.3085 \times 10^{-5} T\left[\ln \left(P_{\mathrm{H}_{2}}\right)+\frac{1}{2} \ln \left(P_{\mathrm{O}_{2}}\right)\right]
\end{array}
$$

The anode and cathode activation overpotentials are calculated from Butler-Volmer equation. The ohmic overpotentials in GDLs and protonic overpotential in membrane are calculated from the potential equations, respectively.

The anode and cathode diffusion overpotentials are calculated as follows:

$$
\begin{aligned}
& \eta_{\text {Diff,c }}=\frac{R T}{2 F} \ln \left(1-\frac{i_{c}}{i_{L, c}}\right) ; \quad \eta_{\text {Diff }, a}=\frac{R T}{2 F} \ln \left(1-\frac{i_{a}}{i_{L, a}}\right) \\
& i_{L, c}=\frac{2 F D_{\mathrm{O}_{2}} C_{\mathrm{O}_{2}}}{\delta_{G D L}} ; \quad i_{L, a}=\frac{2 F D_{\mathrm{H}_{2}} C_{\mathrm{H}_{2}}}{\delta_{G D L}}
\end{aligned}
$$

\section{Hygro-Thermal Stresses in Fuel Cell}

As a result of the changes in temperature and moisture, all the PEM, GDL, and bipolar plates will experience expansion and contraction. Because of the different thermal expansion and swelling coefficients between these materials, hygro-thermal stresses are expected to be introduced. In addition, the non-uniform current and reactant flow distributions in the cell can result in non-uniform temperature and moisture content of the cell, which could in turn, potentially causing localized increases in the stress magnitudes.

Using hygrothermo elasticity theory, the effects of temperature and moisture as well as the mechanical forces on the behavior of elastic bodies have been addressed. An uncoupled theory is assumed, for which the additional temperature changes brought by the strain are neglected. The total strain tensor is determined using the following expression [11]:

$$
\pi=\pi_{M}+\pi_{T}+\pi_{S}
$$

where $\pi_{M}$ is the contribution from the mechanical forces and $\pi_{T}, \pi_{S}$ are the thermal and swelling induced strains, respectively.

The thermal strains resulting from a change in temperature of an unconstrained isotropic volume are given by:

$$
\pi_{T}=\wp\left(T-T_{\operatorname{Re} f}\right)
$$

The swelling strains caused by moisture change in membrane are given by:

$$
\pi_{S}=\lambda_{\text {mem }}\left(\Re-\Re_{\operatorname{Re} f}\right)
$$

Assuming linear response within the elastic region, the isotropic Hooke's law is used to determine the stress tensor:

$$
\sigma=\mathbf{G} \pi
$$

where $G$ is the constitutive matrix. The effective stresses according to von Mises, 'Mises stresses', are given by:

$$
\sigma_{v}=\sqrt{\frac{\left(\sigma_{1}-\sigma_{2}\right)^{2}+\left(\sigma_{2}-\sigma_{3}\right)^{2}+\left(\sigma_{3}-\sigma_{1}\right)^{2}}{2}}
$$

where $\sigma_{1}, \sigma_{2}, \sigma_{3}$ are the principal stresses.

\section{Boundary Conditions}

In order to reduce computational cost, the advantage of the geometric periodicity of the cell is taken. Hence symmetry is assumed in the $y$ direction, i.e. all gradients in the y-direction are set to zero at the $\mathrm{x}-\mathrm{z}$ plane boundaries of the domain. With the exception the channel inlets and outlets, a zero flux condition is applied at all $\mathrm{x}$-boundaries ( $\mathrm{y}$-z planes).

The inlet values at the anode and cathode are prescribed for the velocity, temperature, and species concentrations (Dirichlet boundary conditions). The gas streams entering the cell are fully humidified, but no liquid water is contained in the gas stream. The inlet velocities of air and fuel are calculated based on the desired current density according to:

$$
\begin{aligned}
& u_{i n, c}=\zeta_{c} \frac{I}{4 F} A_{M E A} \frac{1}{x_{O_{2}, \text { in }}} \frac{R T_{i n, c}}{P_{c, i n}} \frac{1}{A_{c h}} \\
& u_{i n, a}=\zeta_{a} \frac{I}{2 F} A_{M E A} \frac{1}{x_{H_{2}, \text { in }}} \frac{R T_{i n, a}}{P_{a, i n}} \frac{1}{A_{c h}}
\end{aligned}
$$

At the outlets of the gas-flow channels, only the pressure is being prescribed as the desired electrode pressure, for all other variables, the gradient in the flow direction (x) is assumed to be zero (Neumann boundary conditions). At the external surfaces in the z-direction, (top and bottom surfaces of the cell), temperature is specified and zero heat flux is applied at the $x-y$ plane of the conducting boundary surfaces. Combinations of Dirichlet and Neumann boundary conditions are used to solve the electronic and protonic potential equations. Dirichlet boundary conditions are applied at the 
land area. Neumann boundary conditions are applied at the interface between the gas channels and the GDLs to give zero potential flux into the gas channels. Similarly, the protonic potential field requires a set of potential boundary condition and zero flux boundary condition at the anode CL interface and cathode CL interface respectively. The mechanical boundary conditions are noted in Figure 1. The initial conditions corresponding to zero stress-state are defined, all components of the cell stack are set to reference temperature $20^{\circ} \mathrm{C}$, and relative humidity 35\% [11, 19]. In addition, a constant pressure of $1 \mathrm{MPa}$ is applied on the surface of lower plate, corresponding to a case where the stack is clamped with springs to control the force.

\section{SOLUTION ALGORITHM}

The governing equations were discretized using a finite volume method and solved using a general-purpose computational fluid dynamic (CFD) code. Stringent numerical tests were performed to ensure that the solutions were independent of the grid size. A computational

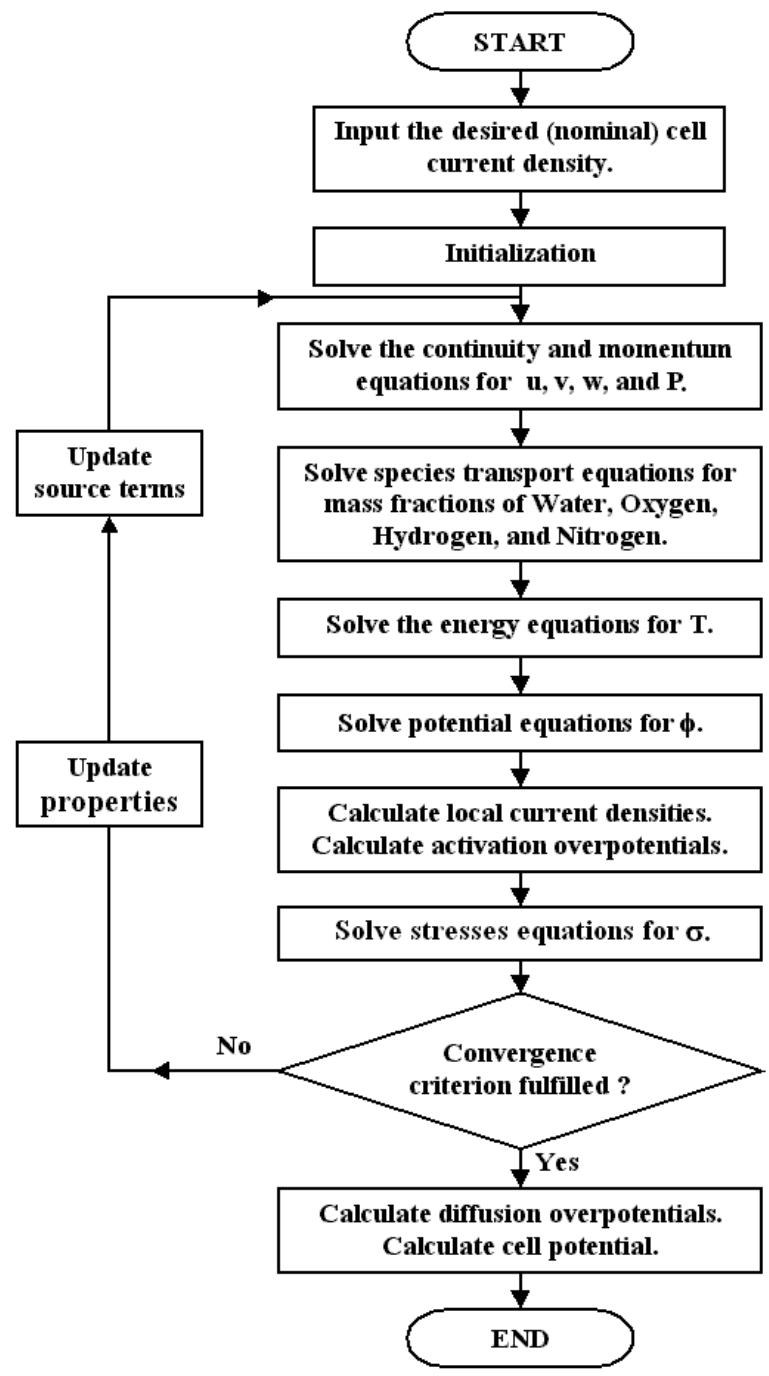

Figure 2. Flow diagram of the solution procedure used mesh of 150,000 computational cells was found to provide sufficient spatial resolution.

Figure 2 shows flow diagram of the solution algorithm used in this study. It begins by specifying a desired current density of the cell for calculating inlet flow rates at the anode and cathode sides. An initial guess of the activation over potential is obtained from the desired current density using the Butler-Volmer equation, then follows by computing the flow fields for each phase for velocities $\mathrm{u}, \mathrm{v}, \mathrm{w}$, and pressure $\mathrm{P}$. Once the flow field is obtained, the mass fraction equations are solved for oxygen, hydrogen, nitrogen, and water. Scalar equations are solved last in the sequence of the transport equations for the temperature field in the cell and potential fields in the GDLs and the membrane.

Hooke's law with total strain tensor is solved to determine the stress tensor. The local current densities are solved based on the Butler-Volmer equation, then local activation over potentials can be calculated from the Butler-Volmer equation. They are updated after each global iterative loop. Convergence criteria are performed on each variable and the procedure is repeated until convergence. The properties are updated after each global iterative loop based on the new local gas composition and temperature. Source terms reflect changes in the overall gas phase mass flow due to consumption or production of gas species via reaction and due to mass transfer between water in the vapor phase and water that is in the liquid phase or dissolved in the polymer.

The set of equations was solved iteratively, and the solution was considered to be convergent when the relative error in each field between two consecutive iterations was less than $10^{-6}$. The number of iterations required to obtain converged solutions dependent on the nominal current density of the cell, the higher the load the slower the convergence.

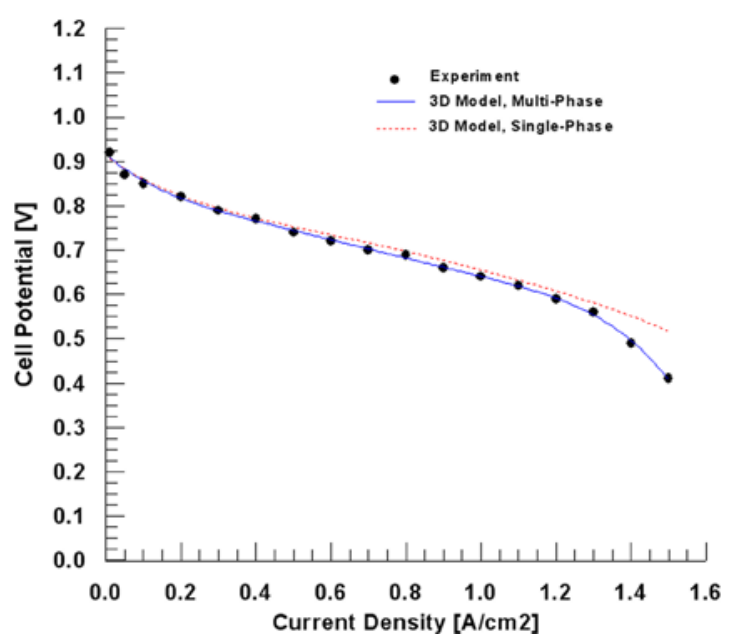

Figure 3. Effect of liquid water build up on cell performance 
Table 1.

Electrode and membrane parameters for base case operating conditions

\begin{tabular}{|c|c|c|c|}
\hline Parameter [Ref.] & Symbol & Value & Unit \\
\hline Electrode porosity [16] & $\varepsilon$ & 0.4 & - \\
\hline Electrode electronic conductivity [5] & $\lambda_{e}$ & 100 & $S / m$ \\
\hline Membrane ionic conductivity (humidified Nafion ${ }^{\circledR} 117$ ) [16] & $\lambda_{m}$ & 17.1223 & $S / m$ \\
\hline Transfer coefficient, anode side [17] & $\alpha_{a}$ & 0.5 & - \\
\hline Transfer coefficient, cathode side [15] & $\alpha_{c}$ & 1 & - \\
\hline Cathode reference exchange current density [3] & $i_{o, c}^{r e f}$ & $1.81 \mathrm{e}-3$ & $A / m^{2}$ \\
\hline Anode reference exchange current density [3] & $i_{o, a}^{r e f}$ & 2465.6 & $A / m^{2}$ \\
\hline Electrode thermal conductivity [4] & $k_{\text {eff }}$ & 1.3 & $W / m \cdot K$ \\
\hline Membrane thermal conductivity [4] & $k_{m e m}$ & 0.455 & $W / m \cdot K$ \\
\hline Electrode hydraulic permeability [14] & $k p$ & $1.76 \mathrm{e}-11$ & $m^{2}$ \\
\hline Entropy change of cathode side reaction [13] & $\Delta S$ & -326.36 & $\mathrm{~J} /$ mole.K \\
\hline Heat transfer coefficient between solid and gas phase [3] & $\beta$ & $4 \mathrm{e} 6$ & $W / m^{3}$ \\
\hline Protonic diffusion coefficient [16] & $D_{H^{+}}$ & $4.5 \mathrm{e}-9$ & $m^{2} / s$ \\
\hline Fixed-charge concentration [16] & $c_{f}$ & 1200 & mole $/ \mathrm{m}^{3}$ \\
\hline Fixed-site charge [16] & $z_{f}$ & -1 & - \\
\hline Electro-osmotic drag coefficient [18] & $n_{d}$ & 2.5 & - \\
\hline Droplet diameter [7] & $D_{\text {drop }}$ & $1 e-8$ & $m$ \\
\hline Condensation constant [7] & $C$ & $1 e-5$ & - \\
\hline Scaling parameter for evaporation [7] & $\varpi$ & 0.01 & - \\
\hline Electrode Poisson's ratio & $\mathfrak{I}_{G D L}$ & 0.25 & - \\
\hline Membrane Poisson's ratio [11] & $\mathfrak{I}_{\text {mem }}$ & 0.25 & - \\
\hline Electrode thermal expansion [11] & $\wp_{G D L}$ & $-0.8 e-6$ & $1 / K$ \\
\hline Membrane thermal expansion [19] & $\wp_{\text {mem }}$ & $123 e-6$ & $1 / K$ \\
\hline Electrode Young's modulus [11] & $\Psi_{G D L}$ & $1 \mathrm{e} 10$ & $\mathrm{~Pa}$ \\
\hline Membrane Young's modulus [19] & $\Psi_{\text {mem }}$ & $249 \mathrm{e} 6$ & $\mathrm{~Pa}$ \\
\hline Electrode density [11] & $\rho_{G D L}$ & 400 & $\mathrm{~kg} / \mathrm{m}^{3}$ \\
\hline Membrane density [19] & $\rho_{\text {mem }}$ & 2000 & $\mathrm{~kg} / \mathrm{m}^{3}$ \\
\hline Membrane humidity swelling-expansion tensor [11] & $\lambda_{\text {mem }}$ & 23e-4 & $1 / \%$ \\
\hline
\end{tabular}

\section{RESULTS AND DISCUSSION}

The values of the electrochemical transport parameters for the base case operating conditions are listed in Table 1. The geometric and the base case operating conditions are listed in Table 2. Since this model accounts for all major transport processes and the domain comprises all the elements of a complete cell, no parameters needed to be adjusted. Performance curves with and without phase change as well as experimental data are shown in Figure 3 for the base case conditions. The experimental data is provided by Wang et al. [14]. Comparison of the two curves demonstrates that the model represents better cell potential $(\mathrm{V})$ versus current density $\left(\mathrm{A} / \mathrm{cm}^{2}\right)$ curve than single phase model. The effects of liquid water accumulation become apparent even at relatively low values of current density. This result validated the developed model. Results with phase change for the cell operates at nominal current density of $1.4 \mathrm{~A} / \mathrm{cm}^{2}$ under the base operating conditions are analyzed and 
Table 2.

Parameters for base case conditions

\begin{tabular}{llll}
\hline Parameter & Symbol & Value & Unit \\
\hline Channel length & $L$ & 0.05 & $m$ \\
\hline Channel width & $W$ & $1 \mathrm{e}-3$ & $m$ \\
\hline Channel height & $H$ & $1 \mathrm{e}-3$ & $\mathrm{~m}$ \\
\hline Land area width & $W_{\text {land }}$ & $1 \mathrm{e}-3$ & $\mathrm{~m}$ \\
\hline GDL thickness & $\delta_{G D L}$ & $0.26 \mathrm{e}-3$ & $\mathrm{~m}$ \\
\hline $\begin{array}{l}\text { Membrane thickness (Nafion }{ }^{\circledR} \\
\text { 117) }\end{array}$ & $\delta_{\text {mem }}$ & $0.23 \mathrm{e}-3$ & $\mathrm{~m}$ \\
\hline Catalyst thickness & $\delta_{C L}$ & $0.028 \mathrm{e}-$ & $\mathrm{m}$ \\
\hline $\mathrm{H}_{2}$ reference mole fraction & $x_{H_{2}}^{\text {ref }}$ & 0.84639 & - \\
\hline $\mathrm{O}_{2}$ reference mole fraction & $x_{O_{2}}^{\text {ref }}$ & 0.17774 & - \\
\hline Anode pressure & $P_{a}$ & 3 & $a t m$ \\
\hline Cathode pressure & $P_{c}$ & 3 & $a t m$ \\
\hline Inlet fuel and air temperature & $T_{c e l l}$ & 353.15 & $\mathrm{~K}$ \\
\hline $\begin{array}{l}\text { Relative humidity of inlet fuel } \\
\text { and air }\end{array}$ & $\psi$ & 100 & $\%$ \\
\hline Air stoichiometric flow ratio & $\xi_{c}$ & 2 & - \\
\hline Fuel stoichiometric flow ratio & $\xi_{a}$ & 2 & - \\
\hline
\end{tabular}

Max. Velocity $=0.00568 \mathrm{~m} / \mathrm{s}$

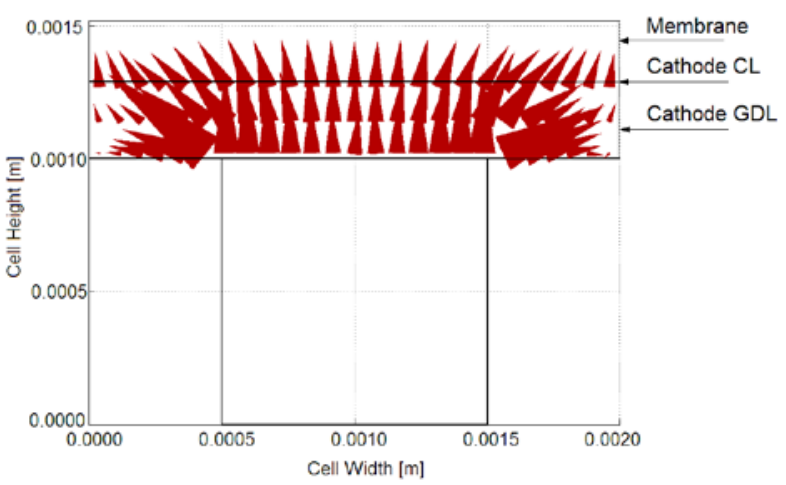

(a)

Max. Velocity $=0.00242 \mathrm{~m} / \mathrm{s}$

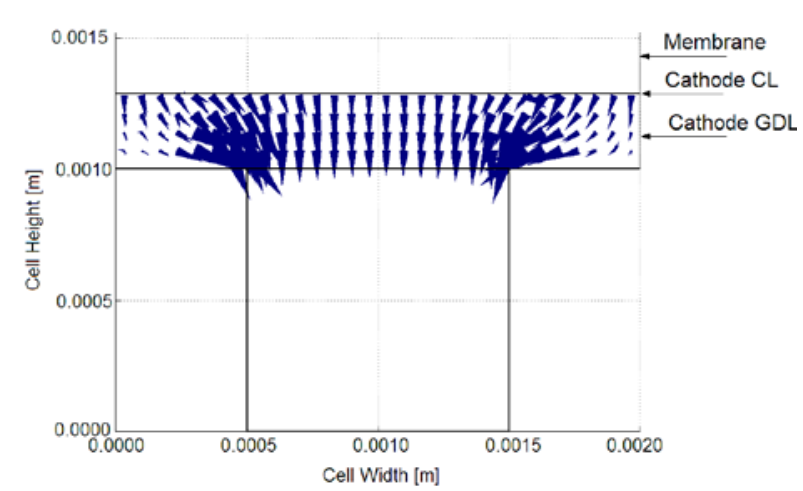

(b)

Figure 4. Velocity vectors inside the cathode GDL: (a) Gas phase velocity vectors; (b) Liquid water velocity vectors

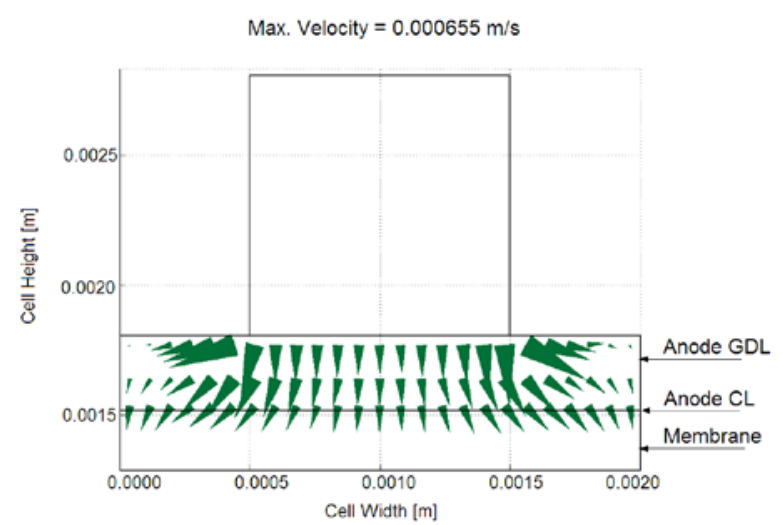

(a)

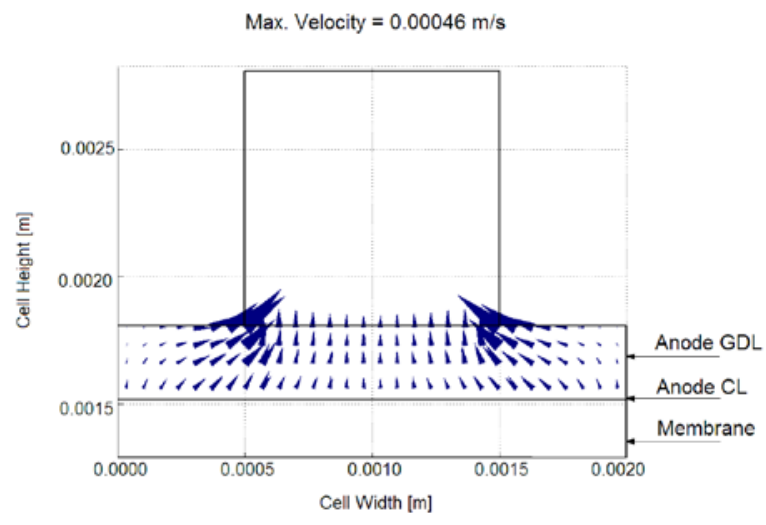

(b)

Figure 5. Velocity vectors inside the anode GDL: (a) Gas phase velocity vectors; (b) Liquid water velocity vectors

discussed in this section. The selection of relatively high current density is due to illustrate the phase change effects, where it becomes apparent between single and multi-phase model in the mass transport limited region.

The velocity fields inside the GDLs are shown in Figures 4 and 5. The liquid water saturation inside the GDL are shown in Figure 6, and the profile of water content in the membrane is shown in Figure 7. These results are newly disclosed here and they have not been presented in the previous papers [20-24]. From Figure 4 and 5 it is clear that the pressure gradient induces bulk gas flow from the channels into the GDL while the capillary pressure gradient drives the liquid water out of the GDL into the flow channels. The velocity of the liquid phase is lower than the gas phase, and the highest liquid water velocity occurs at the corners of the channel/GDL interface.

The liquid water oozes out of the GDL, mainly at the corners of the GDL/channel interface. From Figure 6 it can be observed that condensation occurs mainly in two areas inside the cathodic GDL i.e. at the catalyst layer the molar water vapour fraction increases due to the oxygen depletion, and at the channel/GDL interface, where the oversaturated bulk flow condenses out. Condensation occurs throughout 


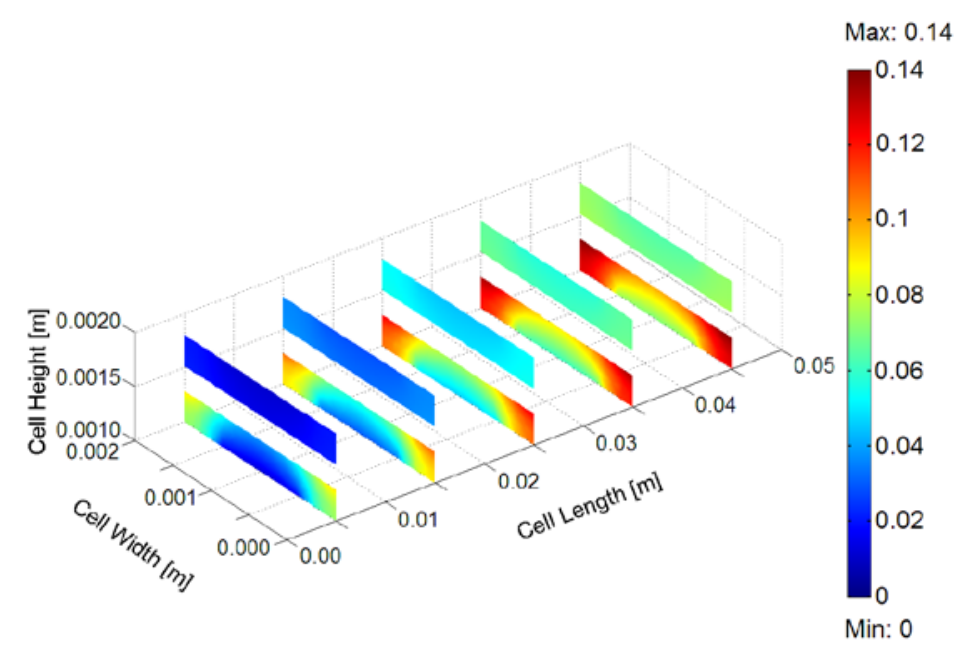

Figure 6. Liquid water saturation inside the GDLs

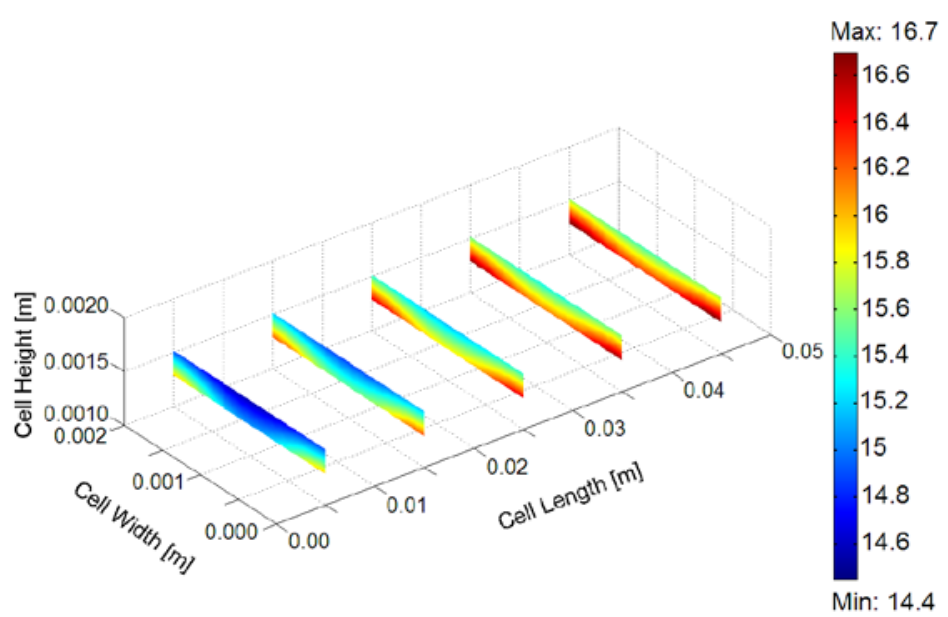

Figure 7. Water content profile through the MEA

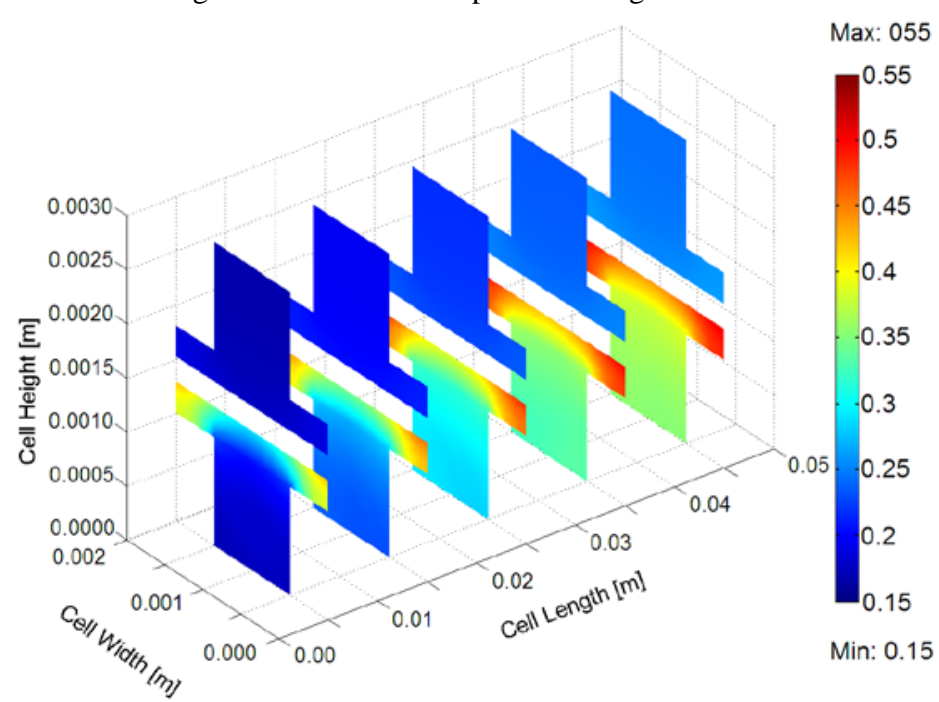

Figure 8. Water vapour molar fraction distribution in the cell at a nominal current density of $1.4 \mathrm{~A} / \mathrm{cm}^{2}$

the anodic GDL due to hydrogen depletion. Similar to the cathode side, the liquid water can only leave the GDL through the build-up of a capillary pressure gradient to overcome the viscous drag, because at steady state operation, all the condensed water has to leave the cell.
The liquid water saturation is distributed through the entire GDL with maximum saturations found under the land areas. The high spatial variation of the saturation demonstrates again the three-dimensional nature of transport processes in PEMFC. Clearly, liquid water saturation depends strongly on the specified 


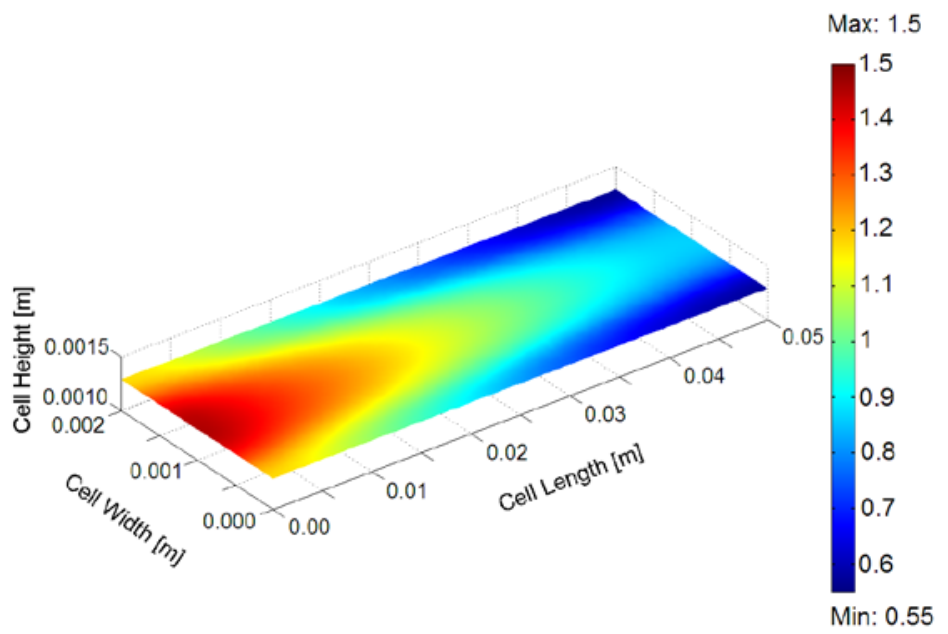

Figure 9. Dimensionless local current density distribution $\left(i_{c} / I\right)$ at the cathode side catalyst layer

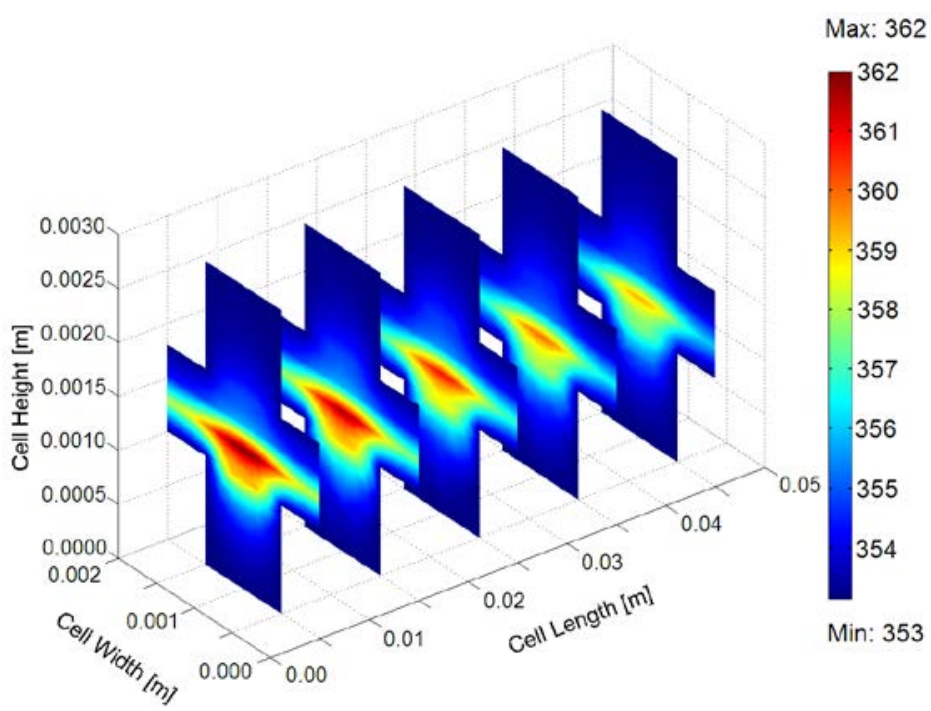

Figure 10. Temperature distribution inside the fuel cell

capillary pressure, and the permeability of the GDL becomes the central parameter. In the membrane, primary transport is through electroosmotic drag associated with the protonic current in the electrolyte, which results in water transport from anode to cathode, and diffusion associated with water-content gradients in the membrane. From Figure 7 it can be noticed that the influence of electro-osmotic drag and back diffusion are apparent.

Water vapour molar fraction distribution is shown in Figure 8. It remains almost constant throughout the GDL. In the absence of phase change, this would not be the case, as the nitrogen and water vapour fraction would increase as the oxygen fraction decreases. Reactant gas distribution in the cell cannels and the GDLs demonstrate similar distribution with those under operation at current density of 0.8 $\mathrm{A} / \mathrm{cm}^{2}$ [24]. They are not plotted in this paper. The molar fraction of oxygen is highest under the channel, and exhibits a three-dimensional behavior with a fairly significant drop under the land areas, and a more gradual depletion towards the outlet. The molar hydrogen fraction is almost constant inside the GDL due to the higher diffusivity of the hydrogen.

The local current density distribution is shown in Figure 9. This result resembles the result reported earlier when the fuel cell was operated at nominal density current of $1.2 \mathrm{~A} / \mathrm{cm}^{2}$ under temperature of $60^{\circ} \mathrm{C}$ and $90^{\circ} \mathrm{C}$ [20]. The differences exist at its magnitude. The maximum value in this study is 1.5 while that in the previous study was 1.4. The local current densities have been normalized by divided through the nominal current density (i.e. $i_{c} / I$ ). In the model it has a much higher fraction of the total current, generated under the channel area. This is due to the effects of liquid water inside the GDL which decreases its permeability to reactant gas flow and lead to the onset of pore plugging by liquid water. This can lead to local hot-spots inside the membrane electrode assembly. This leads to a further drying out of the membrane and increasing the electric resistance, 


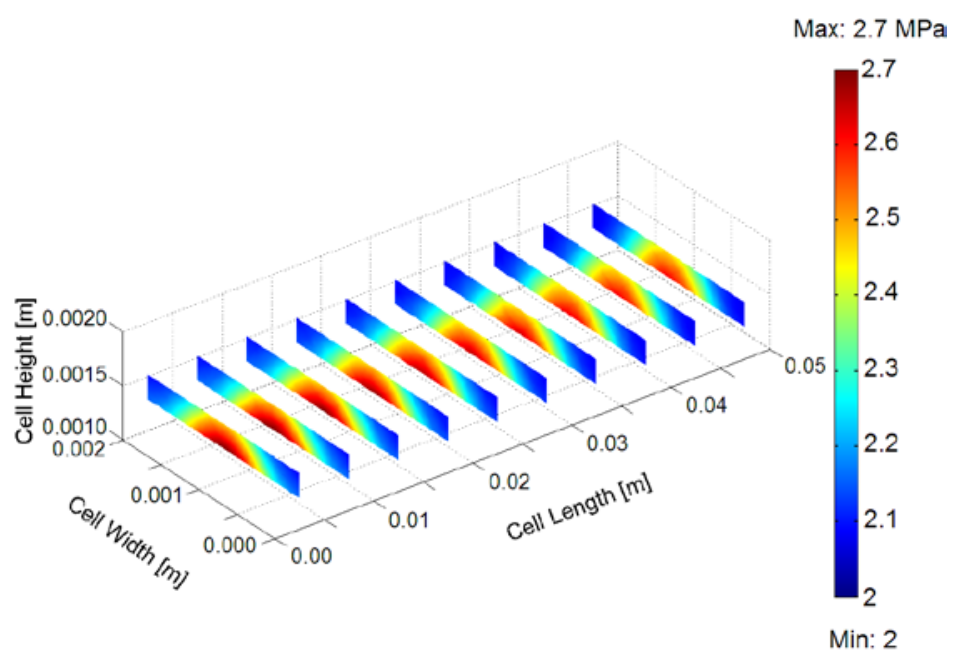

Figure 11. Mises stresses distribution inside the membrane

which in turn leads to more heat generation and can lead to a failure of the membrane. It is important to keep the current density relatively even throughout the cell. Therefore, the model is capable of identifying important parameters for the wetting behavior of the GDLs and can be used to identify conditions that might lead to the onset of pore plugging. The temperature distribution inside the cell has important effects on nearly all transport phenomena, and knowledge of the magnitude of temperature increases might help preventing failure.

Figure 10 shows temperature distribution throughout the $\mathrm{x}$-axis inside the cell at a nominal current density of $1.4 \mathrm{~A} / \mathrm{cm}^{2}$. Temperature distribution only on the $\mathrm{y}-\mathrm{z}$ plane at $\mathrm{x}=10 \mathrm{~mm}$ has been published earlier [23]. From Figure 10 it can be observed that the increase in temperature can exceed several degrees Kelvin near the inlet area, where the electrochemical activity is highest. The temperature peak appears in the cathode CL. In general, the temperature at the cathode side is higher than at the anode side, this is due to the reversible and irreversible entropy production.

Figure 11 shows von Mises stress distribution inside the membrane during the cell operating at base case conditions and a nominal current density of $1.4 \mathrm{~A} / \mathrm{cm}^{2}$. The similar distribution has been published when the cell was operated at nominal density current of $1.2 \mathrm{~A} / \mathrm{cm}^{2}$ [21]. Compared to the previous results Figure 11 shows larger stresses. The maximum stress occurs, where the temperature is highest, which is near the cathode side inlet area.

The Membrane-Electrode-Assembly (MEA) is the core component of PEMFC and consists of membrane with the GDLs including the catalyst attached to each side. Von Misses stress distribution (contours plots) in the cell on the $\mathrm{y}-\mathrm{z}$ plane at $\mathrm{x}=10 \mathrm{~mm}$ at nominal current density of $1.4 \mathrm{~A} / \mathrm{cm}^{2}$ has been published [23]. In this paper the close up of the same distribution is plotted in Figure 12 (scale enlarged 300 times). Because of the different thermal expansion and swelling coefficients between GDLs and membrane materials, hygro-thermal stresses and deformation are introduced. It induces bending stresses which can contribute to delaminating between the membrane and the GDLs.

The distribution of total displacement and deformed shape for MEA at base conditions on the $\mathrm{y}-\mathrm{z}$ plane at $\mathrm{x}=10 \mathrm{~mm}$ are similar to those at nominal current density of $1.2 \mathrm{~A} / \mathrm{cm}^{2}$ [21]. However, the magnitude is different. At nominal current density of $1.4 \mathrm{~A} / \mathrm{cm}^{2}$ larger displacement can be seen. It is related to the temperature where the temperature is highest in the centre of the channel and coincide with the highest reactant concentrations. The deformation under the land areas is much smaller than under the channel areas due to the clamping force effect. This result may explain the occurrence of cracks and pin holes in the membrane under steady-state loading during regular cell operation.

Fuel cell losses originate from sources such as activation overpotential, ohmic overpotential in GDL, membrane overpotential, and diffusion overpotential. When the cell operates at nominal current density of $0.8 \mathrm{~A} / \mathrm{cm}^{2}$ all of these losses have been published [24]. Here, only activation losses are plotted in Figure 13. Table 3 shows comparison of the maximum values of these losses (in Volt) between the two cases of Table 3.

Comparison of maximum losses

\begin{tabular}{lll}
\hline Source of losses & $\begin{array}{l}\text { Current density: } \\
\mathbf{0 . 8}\left(\mathbf{A} / \mathbf{c m}^{2}\right)\end{array}$ & $\begin{array}{l}\text { Current density: } \\
\mathbf{1 . 4}\left(\mathbf{A} / \mathbf{c m}^{2}\right)\end{array}$ \\
\hline Activation & 0.398 (volt) & 0.387 (volt) \\
\hline Ohmic & 0.060 (volt) & 0.086 (volt) \\
\hline Membrane & 0.180 (volt) & 0.250 (volt) \\
\hline Diffusion & 0.065 (volt) & 0.040 (volt) \\
\hline
\end{tabular}




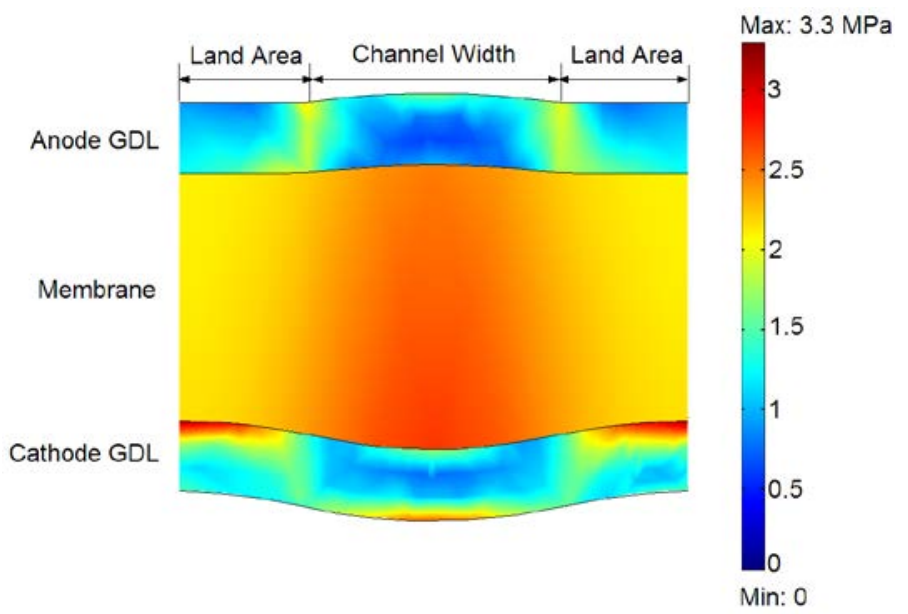

Figure 12. Von Misses stress distribution in MEA

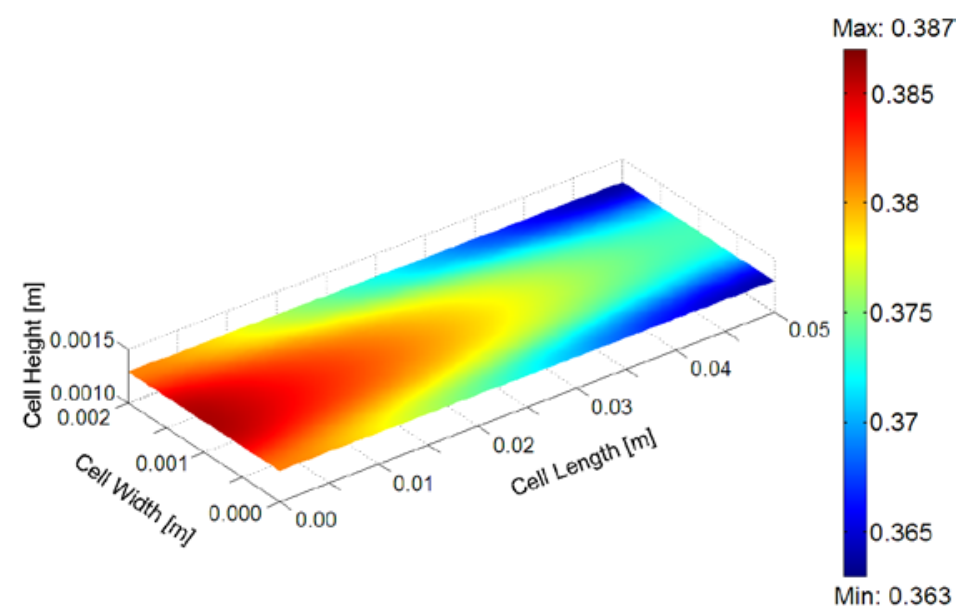

Figure 13. Activation overpotential loss distribution

operating nominal current density. The activation overpotential loss profile at the cathode side CL correlates with the local current density. The current densities are highest in the centre of the channel and coincide with the highest reactant concentrations. It can be seen that the loss is directly related to the nature of the electrochemical reactions. The reaction propagates at the rate demanded by the current.

\section{CONCLUSION}

The developed model has been validated by comparing its results to experimental data. It has been proved that the model represents better cell potential $(\mathrm{V})$ versus current density $\left(\mathrm{A} / \mathrm{cm}^{2}\right)$ curve than single phase model. In the cathodic and anodic GDLs, the velocity of the liquid phase is lower than the gas phase, and the highest liquid water velocity occur at the corners of the channel/GDL interface. The liquid water saturation is distributed through the entire GDL with maximum saturations found under the land areas. The molar water vapour fraction remains almost constant throughout the GDL. The molar fraction of oxygen is highest under the channel, and exhibits a three-dimensional behavior with a fairly significant drop under the land areas, and a more gradual depletion towards the outlet. The molar hydrogen fraction is almost constant inside the GDL due to the higher diffusivity of the hydrogen. The model has been used to analysis important variables at nominal current density of $1.4 \mathrm{~A} / \mathrm{cm}^{2}$. When compared to previous results at nominal current density of $1.2 \mathrm{~A} / \mathrm{cm}^{2}$, the results in this paper shows larger local current density, larger von Mises stresses, and larger displacement. When compared to previous results at nominal current density of $0.8 \mathrm{~A} / \mathrm{cm}^{2}$, the results in this paper show smaller activation losses, larger ohmic losses, larger membrane losses, and smaller diffusion losses. The model is shown to be able to: (1) understand complex phenomena which cannot be studied experimentally, (2) identify limiting steps and components, and (3) provide a computer-aided tool for design and optimization of PEMFC with much higher power density and lower cost.

\section{REFERENCES}

[1] E. E. Kahveci and I. Taymaz, "Experimental investigation on water and heat management in a PEM fuel cell using response surface methodolog," 
International Journal of Hydrogen Energy, 39(20), pp. 10655-10663, 2014.

[2] A. P. Sasmito et al., "Numerical evaluation of various thermal management strategies for polymer electrolyte fuel cell stacks," International Journal of Hydrogen Energy, 36, pp. 12991-13007, 2011.

[3] H. Meng, "Numerical studies of liquid water behaviors in PEM fuel cell cathode considering transport across different porous layer," International Journal of Hydrogen Energy, 35(11), pp. 5569-5579, 2010.

[4] N. K. H. Dalasm et al., "A parametric study of cathode catalyst layer structural parameters on the performance of a PEM fuel cell," International Journal of Hydrogen Energy, 35(6), pp. 2417-2427, 2010.

[5] S. W. Perng, and H. W. Wu, "Nonisothermal transport phenomenon and cell performance of a cathodic PEM fuel cell with a baffle plate in a tapered channel," Applied Energy, 88(1), pp. 52-67, 2011.

[6] A. Iranzo et al., "Numerical model for the performance prediction of a PEM fuel cell. Model results and experimental validation," International Journal of Hydrogen Energy, 35(20), pp. 1153311550, 2010.

[7] N. Djilali, "Computational Modelling of PEM Fuel Cells: Challenges and Possibilities," Energy, 32(4), pp. 269-280, 2007.

[8] M. Hu et al., "Three dimensional, two phase flow mathematical model for PEM fuel cell. Part I. Model development," Energy Conversion Manag, 45(11-12): 1861-1882, 2004.

[9] C. Fink, and N. Fouquet, "Threedimensional simulation of polymer electrolyte membrane fuel cells with experimental validation," Electrochimica Acta, 56(28), pp. 10820-10831, 2011.

[10] A. Webber, and J. Newman, "Theoretical Study of Membrane Constraint in Polymer-Electrolyte Fuel Cell," AIChE J., 50(12), 3215-3226, 2004.

[11] D. Bograchev et al., "Stress and plastic deformation of MEA in running fuel cell," International Journal of Hydrogen Energy, 33, pp. 5703-5717, 2008.

[12] M. A. R. S. Al-Baghdadi, "Performance comparison between planar and tubularshaped ambient air-breathing PEM fuel cells using three-dimensional computational fluid dynamics models," Journal of Renewable and Sustainable Energy; 1(2), pp. 023105-1-023105-15, 2009.

[13] M. A. R. S. Al-Baghdadi, "A CFD analysis of transport phenomena and electrochemical reactions in a tubularshaped ambient air-breathing PEM micro fuel cell," The Hong Kong Institution of Engineers Transactions (HKIE Transactions), 17(2), pp. 1-8, 2010.

[14] M. A. R. S. Al-Baghdadi, "PEM Fuel Cells - from Single Cell to Stack," International Energy and Environment Foundation (IEEF), 2015, ISBN-13: 9781505885644.

[15] M. A. R. S. Al-Baghdadi. "Novel design of a compacted micro-structured airbreathing PEM fuel cell as a power source for mobile phones," International Journal of Energy and Environment; 1(4), pp. 555-572, 2010.

[16] M. A. R. S. Al-Baghdadi, "Analysis of transport phenomena and electrochemical reactions in a micro PEM fuel cell," International Journal of Energy and Environment, 5(1), pp. 1-22, 2014.

[17] M. A. R. S. Al-Baghdadi, "Analysis of transport phenomena and electrochemical reactions in a micro PEM fuel cell with serpentine gas flow channels," International Journal of Energy and Environment, 5(2), pp. 139-154, 2014.

[18] M. A. R. S. Al-Baghdadi, "Analysis of transport phenomena and electrochemical reactions in a micro PEM fuel cell with nature inspired flow field design," International Journal of Energy and Environment; 6(1), pp. 1-16, 2015.

[19] Product Information, DuPont ${ }^{\mathrm{TM}}$ Nafion ${ }^{\circledR}$ PFSA Membranes N115, N117, N1110 Perfluorosulfonic Acid Polymer. NAE101, 2016.

[20] M. A. R. S. Al-Baghdadi, and Haroun A.K.S. Al-Janabi, "Parametric and optimization styudy of a PEM fuel cell performance using three-dimensional computational fluid dynamics model," Renewable Energy (2007), pp. 1077-1101, 32.

[21] M. A. R. S. Al-Baghdadi, and Haroun A.K.S. Al-Janabi, "Effect of operating parameters on the hydro-thermal stresses in proton exchange membrane of fuel cells," International Journal of Hydrogen Energy, 32, pp. 4510-4522, 2007. 
[22] M. A. R. S. Al-Baghdadi, and H. A. K. S. Al-Janabi, "Modeling optimizes PEM fuel cell performance using threedimensional multi-phase computational fluid dynamics model," Energy Conversion and Management, 48, pp. 3102-3119, 2007.

[23] M. A. R. S. Al-Baghdadi, "A CFD study of hygro-thermal stresses distribution in PEM fuel cell during regular cell operation," Renewable Energy, 34, pp. 674-682, 2009.

[24] M. A. R. S. Al-Baghdadi, "Performance comparison between air flow-channel and ambient air-breathing PEM fuel cells using three-dimensional computation fluid dynamics models," Renewable Energy, 34, pp. 1812-1824, 2009.

NOMENCLATURE

\begin{tabular}{|l|l|}
\hline$a$ & water activity \\
\hline$A_{M E A}$ & geometrical area of MEA $\left(\mathrm{m}^{2}\right)$ \\
\hline$A_{c h}$ & cross sectional area of flow channel $\left(\mathrm{m}^{2}\right)$ \\
\hline$C$ & local concentration $\left(\mathrm{mole} / \mathrm{m}^{3}\right)$ \\
\hline$C^{\text {ref }}$ & reference concentration $\left(\mathrm{mole} / \mathrm{m}^{3}\right)$ \\
\hline$C p$ & specific heat capacity $(\mathrm{J} / \mathrm{kg} . \mathrm{K})$ \\
\hline$D$ & diffusion coefficient $\left(\mathrm{m}^{2} / \mathrm{s}\right)$ \\
\hline$E$ & equilibrium thermodynamic potential $(\mathrm{V})$ \\
\hline$E_{c e l l}$ & cell operation potential $(\mathrm{V})$ \\
\hline$F$ & Faraday's constant $=96487\left(\mathrm{C} / \mathrm{mole}^{2}\right)$ \\
\hline$I$ & cell operating current density $\left(\mathrm{A} / \mathrm{m}^{2}\right)$ \\
\hline$i$ & local current density $\left(\mathrm{A} / \mathrm{m}^{2}\right)$ \\
\hline$i_{o,}^{r e f}$ & reference exchange current density \\
\hline$k_{e f f}$ & $\begin{array}{l}\text { effective electrode thermal conductivity } \\
\text { (W/m.K) }\end{array}$ \\
\hline
\end{tabular}

\begin{tabular}{|c|c|}
\hline$k_{m e m}$ & membrane thermal conductivity (W/m.K) \\
\hline$k p$ & hydraulic permeability $\left(\mathrm{m}^{2}\right)$ \\
\hline$\dot{m}_{\text {phase }}$ & mass transfer kg/s) \\
\hline$M$ & molecular weight (kg/mole) \\
\hline$N_{W}$ & net water flux across the membrane $\left(\mathrm{kg} / \mathrm{m}^{2} . \mathrm{s}\right)$ \\
\hline nd & electro-osmotic drag coefficient \\
\hline$n_{e}$ & number of electrons transfer \\
\hline$P$ & pressure $(\mathrm{Pa})$ \\
\hline$P_{c}$ & capillary pressure $(\mathrm{Pa})$ \\
\hline$\dot{q}$ & heat generation $\left(\mathrm{W} / \mathrm{m}^{2}\right)$ \\
\hline$R$ & universal gas constant $=8.314(\mathrm{~J} /$ mole. $\mathrm{K})$ \\
\hline$S$ & specific entropy (J/mole.K) \\
\hline sat & saturation \\
\hline$T$ & temperature $(\mathrm{K})$ \\
\hline $\mathbf{u}$ & velocity vector $(\mathrm{m} / \mathrm{s})$ \\
\hline$x_{i}$ & mole fraction \\
\hline$y_{i}$ & mass fraction \\
\hline$\alpha_{a}$ & charge transfer coefficient, anode side \\
\hline$\alpha_{c}$ & charge transfer coefficient, cathode side \\
\hline$\varepsilon$ & porosity \\
\hline$\eta$ & over potential (V) \\
\hline$\lambda_{e}$ & electrode electronic conductivity (S/m) \\
\hline$\lambda_{m}$ & membrane ionic conductivity (S/m) \\
\hline$\mu$ & viscosity (kg/m.s) \\
\hline$\rho$ & density $\left(\mathrm{kg} / \mathrm{m}^{3}\right)$ \\
\hline$\tau$ & surface tension $(\mathrm{N} / \mathrm{m})$ \\
\hline$\xi$ & stoichiometric flow ratio \\
\hline$\sigma$ & stress $(\mathrm{N} / \mathrm{m})$ \\
\hline$\pi$ & strain \\
\hline $\mathfrak{R}$ & relative humidity (\%) \\
\hline
\end{tabular}

